\title{
The birth of viromics: an interview with Forest Rohwer
}

\author{
Alice Greenway ${ }^{1}$ \& Forest Rohwer*,2 \\ ${ }^{1}$ Future Science Group, London, UK \\ ${ }^{2}$ Department of Biology, San Diego State University, CA 92182, USA \\ *Author for correspondence: frohwer@gmail.com
}

"we have another 5-10 years maybe, at that point we will have a pretty good feel of all the viruses out there"

The editor of Future Microbiology, Alice Greenway, speaks to Forest Rohwer from San Diego State University (CA, USA) following his talk entitled 'Counting all the world's phage' at ASM Microbe 7-11 June 2018.

First draft submitted: 8 August 2018; Accepted for publication: 8 August 2018; Published online:

12 October 2018

Keywords: bacteriophage $\bullet$ immunology $\bullet$ viromics

\section{Could you introduce yourself $\&$ tell us a bit about your background?}

My name is Forest Rohwer, I am a microbial ecologist and Professor of biology at San Diego State University. Mostly I study viruses, particularly bacteriophage. My background is in human immunology and although I am still involved in a lot of human immunology research, I also study phage diversity in the environment.

\section{Some would say you are the father of the field of viromics, could you tell us a bit about the birth of this new field?}

In the early 2000s, we were beginning to get pretty good at sequencing, we had a lot of sequencing potential and people were getting very interested in what was out in the environment and how to study that. Unlike the bacteria, there is nothing like $16 \mathrm{~S}$ for the viruses, so we started shotgun sequencing. This method of randomly sequencing DNA from the environment is what we now call metagenomics. Basically, just start by isolating all the viruses on a sample, shotgun sequencing them and then from that data you could answer, how many are there? Who is there? This area of research in now called viromics.

\section{What are your current research focuses?}

I research two main things, one is what happens in the lungs of cystic fibrosis (CF) patients. We are tying to develop real-time diagnostics and to understand the ecology of the CF lung. Nowadays, we have figured out what happens over time within the lungs of people with CF and how their microbial communities and viral communities interact.

What we do not have a very good feel for is why CF patients go through these different steps toward the end of their life. We are focused on looking at the viruses and mostly, we have found that it is the phage that are really important. Hopefully, we will soon be able to give doctors some new tools to fight against CF and also start manipulating the phage to kill off the bacteria that are becoming problematic at the end of life.

My second research focus is how viruses and bacteria determine the trajectory of the coral reefs. Over the years, we have shown that there is a feedback system stemming from overfishing, which results in an increase of algae, in turn feeding bacteria and causing their numbers to increase. As a result, the bacteria change their relationship with the viruses and the temperate viruses become more abundant, this then creates more pathogens which kill the coral, leaving more space for algae to grow. This is called the dissolved organic carbon, disease, algae, microorganisms (DDAM) feedback system, which is a positive feedback system explaining why a coral reef dies so quickly. Our next steps are to try and find tools that can reverse the cycle.

Future 8 Medicine 


\section{Could you summarize the talk that you are giving at ASM microbe?}

It is a different kind of talk; it is actually part of a memorial for Roger Hendrix and Alan Campbell, two of the leading researchers in the phage community who passed away earlier this year. Roger was heavily involved in unraveling the genomics of phage, much of the early sequencing was done by him, he looked at how phage evolve. He found that phage are a very good model for how things evolve in mosaic fashion. Alan was really instrumental in finding out how phage integrate themselves into their host, called the $\lambda$ model and how that decision is made by the phage. So, my talk really summarizes their work and I also discuss how we have built on their research to where we are now and what the future might look like.

\section{What are the next steps in your research?}

I would say that we are almost done with the global surveys of viral diversity, we have another 5-10 years maybe, at that point we will have a pretty good feel of all the viruses out there. The real challenge is that we do not know what they are doing. Viromics has demonstrated the diversity and abundance. And the numbers are pretty overwhelming, somewhere between 10 and 100 billion viral genes. We do not understand their roles are in the environment. Each virus has a responsibility outside of just killing bacteria; they are constantly doing all sorts of exciting things like moving genes around and modifying behaviors. They are really determining the health trajectory of everything from the CF patients and coral reef. We are going to need to develop some new environmental genetics tools to really figure out their purpose.

\section{Are there any talks/posters that you are particularly interested in here at ASM?}

I have seen a lot of talks, there is definitely a switch to more people being interested in how the temperate phage are influencing either evolution or ecology. There is a very interesting story, that has been going on for a long time, about the Liverpool strain of Pseudomonas, which carries four prophage and how these prophage fight with each other to either keep the host alive or to kill the host. It is a very cool story and it shows how complicated these phage-on-phage bacterial wars can be.

\section{Disclaimer}

The opinions expressed in this interview are those of the interviewee and do not necessarily reflect the views of Future Medicine Ltd.

\section{Financial \& competing interests disclosure}

The authors have no relevant affiliations or financial involvement with any organization or entity with a financial interest in or financial conflict with the subject matter or materials discussed in the manuscript. This includes employment, consultancies, honoraria, stock ownership or options, expert testimony, grants or patents received or pending, or royalties.

No writing assistance was utilized in the production of this manuscript. 